\title{
A RECUSA do “EU” AUTOBIOGRÁFICO EM LES ANNÉES
}

\author{
Raíssa Furlanetto Cardoso ${ }^{1}$
}

\begin{abstract}
RESUMO: Este artigo tem o objetivo de analisar à luz dos artigos "Apparition et disparition du témoin: 'l'autobiographie vide"', de Yvon Inizan (2015), e "Éthique du récit testimonial, Annie Ernaux", de Jérôme Meizoz (2010), como se dá, em Les années, a construção de uma autobiografia impessoal, coletiva e vazia, sem um "eu" e, ao mesmo tempo, a partir de um indivíduo. Com isso, se busca compreender algumas questões que subjazem à escolha da autora de recusar o "eu" justamente em uma autobiografia. Em um primeiro momento, são apresentados o projeto e a estrutura do Les années; em seguida, é analisado como o projeto se concretiza na materialidade do texto e quais são suas consequências enunciativas; por fim, são feitas algumas reflexões sobre como as escolhas metodológicas e enunciativas da autora se inscrevem em sua preocupação ética na construção dessa obra.
\end{abstract}

PALAVRAS-CHAVE: literatura francesa; literatura ultracontemporânea; autobiografia; Annie Ernaux.

\section{THE REFUSAL OF THE AUTOBIOGRAPHIC “|” IN LES ANNÉES}

ABSTRACT: This article aims to analyze in the light of the articles "Apparition et disparition du témoin: 'l'autobiographie vide", by Yvon Inizan (2015), and "Éthique du récit testimonial, Annie Ernaux", by Jérôme Meizoz (2010), how is the construction of Les années' impersonal, collective and empty autobiography, without the usage of "I" and, at the same time, from a singular person. Therewith some issues that are subjacent to the authors choice of refusing to use "l" justly in an autobiography will be presented and understood. Firstly, the Les années project and structure will be presented; afterwards, an analysis on how the project is accomplished and which are its enunciative consequences; and lastly, a reflection about how the author's methodologic and enunciative choices are inserted in the author's ethical posture in the composition of Les années.

KEYWORDS: french literature; ultra-contemporary literature; autobiography; Annie Ernaux.

Les années (2008) de Annie Ernaux é classificado pela Gallimard, editora que o publica, como uma autobiografia. A própria autora diz que suas obras são todas autobiográficas - com exceção de seus três primeiros livros ${ }^{2}$, que trazem a palavra "roman" na capa. Aliás, ela não só afirma que tudo o que escreve é verdade, retirado de sua própria vida, como recusa completamente a ficção. Em 1983, ela manifestou sua descrença no romance e chegou afirmar que ele é impossível (apud MEIZOZ, 2010, p. 114). E, já nos anos 2000, ela ainda mantém sua postura antificcional: ao Ihe perguntarem sobre suas afinidades com o projeto de escrita de Marguerite Duras, ela diferencia-se da autora, que ficcionaliza a própria vida, dizendo que rejeita toda ficção (ERNAUX, 2003, p.60). O mesmo tipo de afirmação também se dá quando Ihe perguntam sobre sua filiação à autoficção ${ }^{3}$ : "Dans l'autofiction, il y a beaucoup de fiction, justement. Et, justement, ce n'est pas mon objet. Ça ne m'intéresse pas! (...) Finalement, je préfère conserver le terme 'autobiographie' bien qu'il me soit difficile de l'utiliser." (ERNAUX, entrevista, 2008).

De fato, Les années é uma autobiografia não apenas pela veracidade de seu conteúdo: nele, o leitor acompanha o decorrer da vida da autora, desde o seu nascimento (1941), até os anos próximos da publicação do livro. Entretanto, há uma especificidade paradoxal nessa obra: contrariamente ao que se espera de uma autobiografia, não há nela nenhum "eu", mas apenas "ela" e "nós", que aparecem intercaladamente. O pronome "ela", que designa a própria autora, implica o

1 Raíssa Furlanetto Cardoso, graduanda em Letras, com habilitação em Português e Francês, na Universidade de São Paulo.

2 Les armoires vides (1974), Ce qu'ils disent ou rien (1977) e La femme gelée (1981).

3 É importante ressaltar que a total rejeição de Ernaux pela autoficção não se dá apenas por causa do seu teor ficcional: "['L'autofiction] c'est un monstre informe, une sorte d'archi-genre, qui recouvre toutes les formes d'écriture du moi et met sous la même bannière des écritures extrêmement diferentes. (...) Ce qui me frappe, en effet, c'est qu'on parle beaucoup plus souvent d'autofiction à propos de textes, quels qu'ils soient, écrits par des femmes et qu'on ne le fait jamais, ou rarement, quand il s'agit de textes d'écrivains masculins auxquels le même label s'appliquerait sans difficulté. Je n'ai jamais entendu le mot 'autofiction' à propos de Philip Roth, Philippe Sollers, Jean Rouaud, Emmanuel Carrère, Frédéric-Yves Jeannet, etc. (...) Tout se passe très subtilement comme si l'autofiction était principalement un genre féminin, avec un côté sentimentalo-trash, narcissique, façon détournée, inconsciente, d'assigner aux femmes leur domaine, leurs limites en littérature." (ERNAUX, entrevista, Le Monde Livres, 2011). 


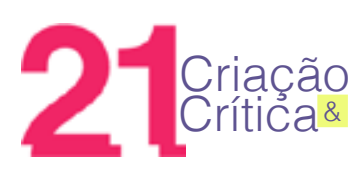

distanciamento, o olhar objetivo dela em relação a si mesma. Já o "nós", que inclui o "eu", inevitavelmente também inclui o "ele"/“eles", o que retira o protagonismo do "eu". Com isso, o tradicional "eu" autobiográfico não aparece como sujeito: ora ele é objeto, ora ele está diluído na coletividade. $\mathrm{Na}$ verdade, como é exposto para o leitor logo na quarta capa da edição de bolso, Les années é uma nova forma de autobiografia, impessoal e coletiva. Impessoal, coletiva e também "vazia", como Annie Ernaux menciona em L'Atelier Noir (2011, p.11).

Neste artigo, será analisado, à luz dos artigos de Yvon Inizan (2015), "Apparition et disparition du témoin: 'l'autobiographie vide"' e de Jérôme Meizoz (2010), "Éthique du récit testimonial, Annie Ernaux", como se dá, em Les années, a construção dessa nova forma de autobiografia, sem um "eu", sem um indivíduo definido e, ao mesmo tempo, a partir de um indivíduo. Com isso, se buscará compreender o que subjaz à recusa do "eu" em uma autobiografia, no contexto da obra de Annie Ernaux.

Em um primeiro momento, serão apresentados o projeto e a estrutura do Les années. Em seguida, se mostrará de que maneira o projeto se concretiza na materialidade do texto para, depois, serem feitas algumas reflexões sobre as escolhas enunciativas da autora na construção dessa obra. Por fim, se buscará inscrever as escolhas metodológicas e enunciativas da autora em sua postura ética de escrita.

\section{Salvar o "nós" a partir do "ela"}

O projeto de escrita do Les années é esboçado em suas últimas páginas. Apenas com uma simples leitura desses trechos finais já seria possível compreender melhor o paradoxo da autobiografia coletiva, impessoal e vazia, pois praticamente tudo é dito ao leitor, tudo é deixado às claras: a motivação e a intenção da autora, sua metodologia de escrita, o efeito desejado, a forma encontrada para obtê-lo.

Ao longo da obra, é possível acompanhar alguns momentos do desenvolvimento da ideia do Les années. Por volta dos anos de 1980, a autora expressa o desejo de escrever algo que fizesse "ressentir le passage du temps en elle et hors d'elle, dans l'Histoire" (ERNAUX, 2008, p.166). Esse desejo vai aumentando, transformando-se, amadurecendo, até que, nas últimas páginas, ele ganha contornos com a definição do projeto mencionado. Por essa razão, a motivação é um dos primeiros elementos que aparecem no projeto, já que ela é consequência da própria história retratada no livro: ao fim da vida, o desejo da autora de recuperar e salvar o que foi vivido e está prester a desaparecer torna-se urgente ${ }^{4}$. A frase que conclui a obra - "Sauver quelque chose du temps où l'on ne sera plus jamais" (ERNAUX, 2008, p.254) - convida o leitor a reler e a repensar o incipit, que proclama o desaparecimento inevitável de tudo - "Toutes les images disparaîtront" (ERNAUX, 2008, p.11) -, pois, na verdade, todas as imagens que estavam condenadas ao desaparecimento foram salvas na escrita e pela escrita.

Esse desejo de apreender a experiência vivida por meio da escrita torna-se urgente justamente quando a autora, já com a idade mais avançada, percebe-se na iminência do fim da vida:

Elle a peur qu'au fur et à mesure de son vieillissement sa mémoire ne redevienne celle, nuageuse et muette, qu'elle avait dans ses premières années de petite fille - dont elle ne se souviendra plus. Déjà, quand elle essaie de se rappeler les collègues du

4 "Saisir la lumière qui baigne des visages désormais invisibles" (ERNAUX, 2008, P.254) 


\section{1}

lycée de montagne où elle a enseigné deux ans, elle revoit des silhouettes, des figures, parfois avec une extrême précision, mais il lui est impossible de "mettre un nom dessus". Elle s'acharne à retrouver le nom manquant, à faire coïncider une personne et un nom, comme raccorder deux moitiés séparées. Peut-être un jour ce sont les choses et leur dénomination qui seront désaccordées et elle ne pourra plus nommer la réalité, il n'y aura que du réel indicible. C'est maintenant qu'elle doit mettre en forme par l'écriture son absence future, entreprendre ce livre, encore à l'état d'ébauche et de milliers de notes, qui double son existence depuis plus de vingt ans, devant couvrir du même coup une durée de plus en plus longue. (ERNAUX, 2008, p.249).

A memória falha, tornando-se muda, a impossibilidade de nomear a realidade e o esquecimento do que um dia foi tão presente, sinalizam o completo desaparecimento da realidade vivida. $A$ consciência da autora de que, por exemplo, as experiências dos avós de seus pais foram completamente extintas - salvaram-se apenas alguns gestos, talvez uns poucos hábitos - a fazem ter certeza de que o mesmo ocorrerá com ela, caso ela não empreenda a escrita desse livro.

$\mathrm{Na}$ verdade, esse medo de que tudo irá desaparecer com a perda da capacidade de nomear a realidade traduz-se no fato de que não existe experiência humana fora da linguagem (BENVENISTE, 1995). Em outras palavras, sem a memória e, principalmente, sem a capacidade de verbalizar essas memórias por meio da linguagem, não há experiência.

A linguagem é a condição absolutamente indispensável para a existência do pensamento e para constituição dos seres humanos enquanto sujeitos:

Esse conteúdo [do pensamento] recebe forma quando é enunciado, e somente assim. Recebe forma da língua e na língua, que é o molde de toda expressão possível; não pode dissociar-se dela e não pode transcendê-la. Ora, essa língua configura-se no seu conjunto e enquanto totalidade. É, além do mais, organizada como combinação de "signos" distintos e distintivos, susceptíveis, eles próprios, de decomporse em unidades inferiores ou de agrupar-se em unidades complexas. Essa grande estrutura, que encerra estruturas menores e de muitos níveis, dá a sua forma ao conteúdo de pensamento. Para tornar-se transmissível, esse conteúdo deve ser distribuído entre morfemas de certas classes, organizadas numa certa ordem, etc. Enfim, esse conteúdo deve passar pela língua e tomar-lhe os quadros. De outro modo o pensamento se reduz, se não a nada, pelo menos a algo de tão vago e de tão indiferenciado que não temos nenhum meio de apreendê-lo como "conteúdo" distinto da forma que a língua lhe confere. (BENVENISTE, 1995, p.69)

É na linguagem e pela linguagem que o homem se constitui como sujeito; porque só a linguagem fundamenta na realidade, na sua realidade que é a do ser, o conceito de "ego" (BENVENISTE, 1995, p.286).

Sem a linguagem não há sujeito, não há pensamento e, portanto, não há experiência. Desse modo, esquecer a realidade vivida e não poder mais nominá-la, não significa simplesmente a morte, 


\section{1}

mas nunca ter existido. Nesse sentido, a escrita do Les années surge como a maneira de salvar a experiência da morte e de um tempo em não se será mais nada, nunca mais (ERNAUX, 2008, p.249).

Escrever, então, significa, no contexto do Les annéees, continuar existindo na escrita e pela escrita. Ao mesmo tempo, porém, não se trata aqui de rememorar e escrever a própria vida, de salvar-se apenas a si mesmo, com o fim de chegar a uma explicação de si $^{5}$. Como é exposto no projeto de escrita, a intenção da autora, para além de apreender a sua passagem pela terra a uma certa época, é a de apreender o tempo que a atravessou, o mundo que ela registrou apenas vivendo ${ }^{6}$. Em outras palavras, ela quer reconstituir o que o mundo imprimiu nela e em seus contemporâneos e salvar um tempo comum. Não se trata nem de reconstituir a vida de um só indivíduo e nem a História do mundo, mas de "rendre la dimension vécue de l'Histoire" (ERNAUX, 2008, p.251). Com isso, o olhar para a própria experiência vivida não é mais do que a maneira pela qual a autora irá encontrar a memória da memória coletiva: "Elle ne regardera en elle-même que pour y retrouver le monde, la mémoire et l'imaginaire des jours passés du monde, saisir le changement des idées, des croyances et de la sensibilité, la transformation des personnes et du sujet, qu'elle a connus" (ERNAUX, 2008, p.251). Fica claro que, para que isso ocorra, é primordial que a autora tenha um olhar objetivo, impessoal e distanciado em relação a si própria: um dos motivos pelos quais ela substitui "eu" por "ela" e "nós".

Esse procedimento é evocado em uma passagem do início do livro que evidencia tanto a distância entre a autora/narradora e o "ela", quanto a busca do coletivo no individual:

Et c'est avec les perceptions et les sensations reçues par l'adolescente brune à lunettes de quatorze ans et demi que l'écriture ici peut retrouver quelque chose qui glissait dans les années cinquante, capter le reflet projeté sur l'écran de la mémoire individuelle par l'histoire collective. (ERNAUX, 2008, p.56)

Como é esboçado no projeto do livro, o resultado desse desejo de salvar a memória coletiva a partir da própria memória manifesta-se na mistura de "arrêts sur mémoire" com "récit glissant", de "ela" com "nós":

Ce sera un récit glissant, dans un imparfait continu, absolu, dévorant le présent au fur et à mesure jusqu'à la dernière image d'une vie. Une coulée suspendue, cependant, à intervalles réguliers par des photos et des séquences de films qui saisiront les formes corporelles et les positions sociales successives de son être - constituant des arrêts sur mémoire en même temps que des rapports sur l'évolution de son existence, ce qui l'a rendue singulière, non par la nature des éléments de sa vie, externes (trajectoire sociale, métier) ou internes (pensées et aspirations, désir d'écrire), mais par leur combinaison, unique en chacun. À cette "sans cesse autre" des photos correspondra, en miroir, le "elle" de l'écriture.

5 "Ce ne sera pas un travail de remémoration, tel qu'on l'entend généralement, visant à la mise en récit d'une vie, à une explication de soi” (ERNAUX, 2008, p.251).

6 "Ce qui compte pour elle, c'est au contraire de saisir cette durée qui constitue son passage sur la terre à une époque donnée, ce temps qui l'a traversée, cemonde qu'elle a enregistré rien qu'en vivant. " (ERNAUX, 2008, p.250) 


\section{1}

Aucun "je" dans ce qu'elle voit comme une sorte d'autobiographie impersonnelle - mais "on" et "nous" - comme si, à son tour, elle faisait le récit des jours d'avant. (ERNAUX, 2008, p.252)

Cada período abordado em Les années - entre os anos 1940 e 2000 - é separado por espaçamentos triplos. No início de cada um há uma descrição de foto em que o "ela" aparece (há também de vídeos, mas apenas dois). A autora, então, descreve não só a foto em si, como também os sentimentos, comportamentos e desejos desse "ela" naquele contexto. Apenas depois da foto "emoldurar" a época, é que "ela" é substituído por "nós" e que são descritos, citados ou listados certos hábitos, ideias ou fatos (políticos, econômicos, culturais, sociais...) comuns ao tempo da foto. Desse modo, o mecanismo de busca do coletivo no individual opera na própria estruturação do livro.

\section{O “ela" autobiográfico}

Fica implícito no projeto de escrita que, ao longo do Les années, o "ela" aparece nos "intervalos", nos "arrêts sur mémoire" proporcionados pelas fotos (e pelos dois vídeos também). Como já foi mencionado, esse "ela" é visto de maneira distanciada, objetiva, pois não é a intenção da autora simplesmente falar de si mesma. De fato, nas descrições de fotos, poucas de suas características físicas são mencionadas: apenas a cor do cabelo, alguns traços do rosto e as roupas mais nenhum detalhe que permita reconstituir nitidamente sua imagem. A autora descreve ainda a sua postura na foto e a atitude a ela subjascente para, em seguida, comentar alguns aspectos subjetivos que, porém, nunca são desenvolvidos.

La photo en noir et blanc d'une petite fille en maillot de bain foncé, sur une plage de galets. En fond, des falaises. Elle est assise sur un rocher plat, ses jambs robustes étendues bien droites devant elle, les bras en appui sur le rocher, les yeux fermés, la tête légèrement penchée, souriant. Une épaisse natte brune ramenée par-devant, l'autre laissée dans le dos. Tout révèle le désir de poser comme les stars dans Cinémonde ou la publicité d'Ambre Solaire, d'échapper à son corps humiliant et sans importance de petite fille. (...) Au dos: août 1949, Sotteville-sur-Mer. (ERNAUX, 2008, p.35)

L'autre femme, à l'extrémité gauche, d'âge mûr incertain - des rides sur le front touché par la lumière, des taches roses de blush sur les pommettes, contour amolli du visage - des cheveux coupés au carré, un pull beige avec un foulard noué lâchement, une perle à l'oreille, un sac en bandoulière, évoque la citadine aisée des week-ends sur la côte normande.

Elle a le sourire, doux et distant, de ceux qui, parent ou prof, sont photographiés seuls avec des jeunes (une façon de montrer qu'on n'est pas dupe de la différence de génération). (...) Au dos, Trouville, mars 1999. (ERNAUX, 2008, p.210)

De fato, a foto não é um recurso utilizado para fazer emergir a singularidade daquele "ela", mas, pelo contrário, como Inizan (2015) sublinha, citando a própria Ernaux, seu papel é essencial para a objetificação do olhar da autora: 


\section{1}

Et puis j'ai pensé à décrire dans le texte des photos de moi, mais en disant "elle", ce qui était une manière d'introduire un corps de femme, une histoire de femme dans le texte, et donc d'incarner réellement le passage des années. C'est ainsi que le récit s'est mis à "fonctionner" (apud INIZAN, 2015, p.12).

Assim, as fotos têm a função de "encarnar" a passagem do tempo, de dar materialidade e veracidade ao período retratado e, assim, de ancorar a memória em um tempo preciso: daí o uso do presente nesses "arrêts sur mémoire", que contribui para que o próprio leitor se transporte, junto à autora, para o tempo da foto. Além disso, o uso da foto - que é pessoal e, portanto, "verídico" inscreve-se na postura ética da autora de recusa da ficcionalização da vida.

Para Annie Ernaux, as fotos também são importantes para que ela consiga rememorar as suas sensações naquele período de sua vida. E é a rememoração de sensações que serve de ponto de partida para a sua busca da memória coletiva naquela memória individual. É como se a autora conseguisse, por meio da escrita, fotografar as sensações de um tempo passado, antes informes e mudas, apenas encarnadas nas imagens, e trazê-las objetivamente para o presente da escrita. Assim, a foto, mais do que um ponto de referência no tempo, torna-se também um ponto de referência para que a autora encontre a sua relação com o mundo naquele momento, e, assim, encontre o próprio mundo.

As sensações produzidas pelas fotos do período da infância e da adolescência são bastante ilustrativas de como a autora trata suas próprias experiências de maneira distanciada, sem aprofundá-las:

En faisant ses devoirs, elle écoute les chansons du poste dont elle écrit les paroles dans un carnet et qu'elle porte dans la tête des journées entières en marchant, en suivant les cours, toi qui disais que tu l'aimais qu'as-tu fait de ton amour pour qu'il pleure sous la pluie.

Elle ne parle pas aux garçons, elle y pense tout le temps. Elle voudrait avoir le droit de mettre du rouge à lèvres, porter des bas et des talons hauts. (ERNAUX, 2008, p.57)

Quand elle entend les petites filles des classes enfantines chanter dans la cour de récréation Cueillons la rose sans la laisser flétir, il lui semble qu'elle a été enfant il y a très longtemps. (ERNAUX, 2008, p.60)

Sans doute elle ne pense qu'à elle, (...) notant dans un calepin des phrases qui disent comment vivre - qu'elles soient dans des livres leur assure un poids de vérité, il n'y a de bonheur réel que celui dont on se rend compte quand on en jouit (ERNAUX, 2008, p.68)

Nos exemplos citados, embora as sensações venham de experiências individuais, elas são, ao mesmo tempo, bastante gerais: o corte com a infância, o egocentrismo, a autodescoberta, a tentativa de autodefinição, sentir-se mais maduro do que as crianças mais novas ou procurar frases e músicas impactantes que definem a vida são atitudes bastante comuns na adolescência. Não há uma narrativa por traz dessas sensações, não há elementos que as singularizem, que as tornem únicas, específicas da vida da autora. As músicas - grafadas em itálico pela autora 


\section{1}

-, que até poderiam ser vistas como um traço de singularidade da memória, são, na verdade, pertencentes ao imaginário coletivo, são "trilhas sonoras" de um período. Para Annie Ernaux, as músicas funcionam mais como uma forma de evocar um ano, de contextualizá-lo:

II y a peu de textes où je n'évoque pas des chansons, parce qu'elles jalonnent toute ma vie et que chacune ramène des images, des sensations, une chaîne proliférante de souvenirs, et le contexte d'une année : "La Lambada" de l'été 1989, "I Will Survive" de 1998, "Mexico" et "Voyage à Cuba" de 1952. Ce sont des "madeleines" à la fois personnelles et collectives. (ERNAUX, 2003, p.29)

Talvez fosse possível pensar que, como a própria infância e a adolescência são períodos de indefinição e de construção do sujeito, as sensações tenderiam, naturalmente, a ser mais universais. Porém, mesmo quando a autora vai entrando na vida adulta e as sensações vão se tornando um pouco mais específicas, mais complexas, ainda assim elas não se singularizam.

Em alguns momentos, a subjetividade quase chega a emergir no texto. No trecho seguinte, por exemplo, há transcrições do diário da autora - um dos únicos momentos em que o "eu" aparece:

À certains moments, elle éprouve un accablement devant la somme de ce qu'elle a appris. Son corps est jeune et sa pensée vieille. Dans son journal intime, elle a écrit qu'elle se sent "sursaturée d’idées passe-partout, de théories", qu'elle est "à la recherche d'un autre langage", désirant "retourner à une pureté première", elle rêve d'écrire dans une langue inconnue. Les mots lui sont "une petite broderie autour d'une nappe de nuit". D’autres phrases contredisent cette lassitude: "Je suis un vouloir et un désir". Elle ne dit pas lesquels. (ERNAUX, 2008, p.91)

Ainda que as citações do diário aproximem o texto da subjetividade da autora, a frase que fecha o parágrafo, "Elle ne dit pas lesquels", seguida por ponto final e por um espaçamento antes do início do próximo parágrafo - que já trata de outros assuntos -, corta completamente um possível mergulho mais profundo nessa interioridade. Sabe-se que se trata de uma jovem confusa, imatura, que se interessa por literatura, mas nada muito além disso. Quais são exatamente seus anseios e desejos, o que os originou, qual caminho ela irá escolher daquele momento em diante... A autora não diz e nem busca redescobri-los.

Em outros momentos, surgem, junto às sensações, memórias bastante específicas:

La nuit, dans l'hôtel Escurial à Tolède, réveillée par des gémissements, elle a couru vers la chambre des enfants, à côté. Ils dormaient tranquillement. Retournée se coucher, elle et son mari se sont rendu compte que c'était une femme qui jouissait interminablement, ses cris répercutés par les murs du patio dans toutes les chambres aux fenêtres ouvertes. Elle n'a pu s'empêcher de se masturber à côté de son mari rendormi. (ERNAUX, 2008, p.148)

Les moments importants de son existence actuelle sont les rencontres avec son amant l'après-midi dans une chambre d'hôtel rue Danielle-Casanova et les visites à sa mère à 


\section{1 tringaga}

l'hôpital, en long séjour. Les deux sont tellement liées qu'elles lui semblent parfois concerner un seul être. Comme si toucher la peau et les cheveux de sa mère égarée était de même nature que les gestes érotiques avec son amant. (ERNAUX, 2008, p.165)

Mesmo nesses casos, há uma lacuna, um vazio, que não permitem que as memórias tragam à tona de maneira efetiva a singularidade da autora enquanto indivíduo. No primeiro trecho citado, não se sabe de mais nada dessa viagem, nem seu contexto, nem quando aconteceu, nem como foi, nem quanto tempo durou. No segundo, também não é dito quem é esse amante, como eles se conheceram, como o relacionamento terminou, ou, então, quando a mãe foi para o hospital, quanto tempo ficou lá, qual a relação da autora com ela, quais seus sentimentos etc. Assim como ocorre em todas as outras memórias, os fatos não têm um desenvolvimento, não têm relação de causa e consequência uns com os outros. Desse modo, eles funcionam mais como uma forma de retratar o modo como "ela" se relaciona com o mundo naquele momento da vida e como uma maneira de introduzir, de "preparar", a entrada no "nós" no texto.

O corte brusco com as sensações e memórias da autora ocorre também porque os trechos com "ela" são antecedidos e seguidos por aqueles que trazem o "nós", de forma que, quando se começa a se aproximar mais da menina ou da mulher retratada, logo se é levado ao encontro das coletividades que a cerca.

Enfim, os trechos com "ela" formam-se por uma reunião de parágrafos-foto de sensações e de memórias suscitadas pelas fotografias pessoais da autora. São parágrafos que começam e terminam em si mesmos, sem uma relação de causalidade com os demais parágrafos que possa delinear alguma narrativa da história da autora ou a sua identidade. Com isso, o olhar sobre "ela" mantém-se objetivo, distanciado e impessoal, de modo que a subjetividade nunca se sobreponha ao "nós", deixando que ele ganhe espaço no texto.

Annie Ernaux constrói, assim, uma autobiografia impessoal e, também, vazia, ou seja, a partir de um "ela" autobiográfico, mas esvaziado da subjetividade e da singularidade do "eu":

Comment passer du singulier au général? "Commencer un livre - remarque Annie Ernaux - c'est sentir le monde autour de moi, et moi comme dissoute, acceptant de me dissoudre, pour comprendre et rendre la complexité du monde". On découvre la volonté de décrire un monde, et, dans la description elle-même, l'effort pour dissiper le sujet qui a vécu ce monde: objective, l'autobiographie doit alors se vider." (INIZAN, 2015, p.3).

Uma vez "dissolvida" no mundo, esvaziada de contornos e particularidades, o "ela" objetivo pode servir de fonte para encontrar o coletivo e, então, ceder o espaço para o surgimento do "nós".

\section{O “nós" autobiográfico}

Enquanto os "arrêts sur mémoire" trazem o "ela", os "récits glissants" trazem o "nós". Essas partes do texto são compostas por cenas ocorridas em espaços públicos, trechos de música, menção a filmes, propagandas, vozes e gestos, que algumas vezes se misturam e se confundem com as memórias domésticas, particulares, do "ela". 


\section{1}

O tempo utilizado é o imperfeito e não mais o presente: com isso, o leitor é imerso em um passado contínuo, indefinido. A construção das frases também cria um ritmo que acompanha esse movimento do imperfeito. Por vezes, ela se dá pela seguida repetição de "nós":

Mais nous, à la différence des parents, on ne manquait pas l'école pour semer du colza, locher des pommes et fagoter du bois mort. Le calendrier scolaire avait remplacé le cycle des saisons. (...) À la rentrée on couvrait de papier bleu les livres d'occasion légués par les élèves de la classe d'avant. En regardant leur nom mal effacé sur la page de garde, les mots qu'ils avaient soulignés, on avait l'impression de prendre leur relais et d'être encouragés, par eux qui en étaient venus à bout, à savoir en un an toutes ces choses. On apprenait des poésies de Maurice Rollinat, Jean Richepin, Émile Verhaeren, Rosemonde Gérard, des chants, Mon beau sapin roi des forêts, C'est lui le voilà le dimanche avec sa robe de mai nouveau. On s'appliquait à faire zéro faute aux dictées de Maurice Genevoix, La Varende, Émile Moselly, Ernest Pérochon. Et l'on récitait les règles de grammaire du bon français. (ERNAUX, 2008, p.34)

Em outros momentos, as frases são mais longas, listando substantivos e verbos no infinitivo:

II semblait qu'on pouvait s'emparer de la totalité des connaissances, entrer dans la multiplicité des points de vue jetés sur les blogs dans une langue neuve et brutale. S'informer sur les symptômes du cancer de la gorge, la recette de la moussaka, l'âge de Catherine Deneuve, la météo à Osaka, la culture des hortensias et du cannabis, l'influence des Nippons sur le développement de la Chine - jouer au poker, enregistrer des films et des disques, tout acheter, des souris blanches et des revolvers, du Viagra et des godes, tout vendre et revendre. Discuter avec des inconnus, insulter, draguer, s'inventer. (ERNAUX, 2008, p. 233)

Ou, ainda, elas se constroem à maneira de listas propriamente ditas:

Les voix transmettaient un héritage de pauvreté et de privation antérieur à la guerre et aux restrictions, plongeant dans une nuit immémoriale, "dans le temps", dont elles égrenaient les plaisirs et les peines, les usages et les savoirs :

habiter une maison en terre battue

porter des galoches

jouer avec une poupée de chiffon

laver le linge à la cendre de bois

accrocher à la chemise des enfants près du nombril un petit sac de tissu avec des gousses d'ail pour chasser les vers

obéir aux parents et recevoir des calottes, il aurait fait beau répondre. (ERNAUX, 2008, pp.29-30)

De qualquer modo, os parágrafos vão acumulando diversos aspectos de uma época: as ideias do senso comum, o contexto político, os hábitos e costumes, a moda, a cultura, os gostos - todos 


\section{1 tringaga}

fatores que ultrapassam a individualidade do "ela" e fazem parte de uma memória comum. Assim, como é dito no projeto de escrita, o texto transforma-se em um "récit des jours d'avant", mesclando características de um determinado período e sentimentos e práticas coletivas.

Com o acúmulo de "nós", de imperfeitos, de infinitivos, de substantivos e com o ritmo contínuo, absoluto, que devora o presente, criam-se espécies de "ondas" que submergem o texto em um continuum indefinido no tempo, recriando a atmosfera de uma época, tal qual ela é sentida por uma coletividade. Então, se nos trechos com "ela" é como se o leitor estivesse diante de fotografias de sensações, nos trechos em "nós" é como se ele pudesse ver diversas cenas de um filme de época, em que a sucessão de memórias, práticas, acontecimentos e experiências coletivas, compõem o cenário. Desse modo, vai se contruindo ao longo da obra uma autobiografia coletiva. $E$, nesse sentido, a impessoalidade da autobiografia se manifesta também porque ela é coletiva, não pertencente a uma pessoa específica.

É importante ressaltar que, em Les années, não há uma coletividade, unívoca. O "nós" autobiográfico designa, alternadamente, as diversas coletividades a qual a autora já fez ou faz parte: camponeses, classe média, intelectuais, "desertores de classe", mulheres, estudantes (da escola e da faculdade), entre outras. Então, na verdade, a autobiografia coletiva constrói-se em estreita relação com as diversas experiências da autora em cada um de seus lugares sociais. Como consequência disso, o único "nós" que aparece ao longo de todo o livro é o que designa as mulheres. Não aparece "nós" em referência a "estudantes" quando a autora já tem a idade mais avançada, por exemplo; ou o "nós" significando "os camponeses" após o seu casamento com um "burguês"; ou, ainda, o "nós" significando "a classe média", ou "os intelectuais" quando ela ainda é menina.

Muitas das experiências individuais da autora são consequência do seu lugar social. Por exemplo: em sua condição de camponesa, ela sente uma grande diferença em relação às colegas da escola de classe média; enquanto uma "desertora de classe", ela não se sente parte nem do meio burguês, nem do meio camponês; enquanto menina, ela percebe as disparidades em relação aos meninos, e, mais tarde, enquanto mulher, em relação ao marido. Esses tipos de experiências são, geralmente, exemplares e, portanto, coletivas, compartilhadas por muitos que estão no mesmo lugar social da autora. A exemplaridade fica mais evidente, principalmente, quando Annie Ernaux aborda suas experiências enquanto mulher na sociedade. No trecho a seguir, ela parte da sua própria vivência para fazer uma correlação direta com a das mulheres de modo geral (que, aliás, é a de muitas, até hoje):

Selon les critères des journaux féminins, extérieurement elle fait partie de la catégorie en expansion des femmes de trente ans actives, conciliant travail et maternité, soucieuses de rester féminines et à la mode. Énumérer les lieux qu'elle fréquente dans une journée (collège, Carrefour, boucherie, pressing, etc.), ses trajets dans une Mini Austin entre le pédiatre, le judo de l'aîné et la poterie du cadet, la Poste, calculer le temps dévolu à chaque occupation, cours et corrections, préparation du petit déjeuner, des vêtements des enfants, du linge à laver, du déjeuner, courses, sauf le pain - c'est lui qui le rapporte au retour du travail - ferait apparaître:

7 Possível tradução para "transfuges de classes", ou seja, pessoa que nasceu em um certo meio social e na vida adulta passou a viver em outro. 


\section{1}

un partage apparemment inégal entre le dedans et le dehors de la maison, le travail salarié (2/3) et le travail domestique, y compris éducatif (1/3)

une grande diversité des tâches

une importante fréquentation des lieux de commerce

une absence quasi totale de temps mort. (ERNAUX, 2008, p.125)

Ao lado dessas experiências ao mesmo tempo individuais e coletivas, aparecem também experiências essencialmente coletivas, mais amplas, consequência de movimentos da história, de transformações da sociedade, da política, da economia: mudanças ideológicas e de comportamento da classe média, conquistas das mulheres, novas configurações familiares, novas relações nos almoços de família etc.

Além de surgir por meio das experiências coletivas, a memória coletiva também aparece, muitas vezes, diretamente atrelada à memória individual, ao modo como "ela" recebeu os acontecimentos:

Elle n'oubliera jamais ni la date de l'insurrection algérienne ni cet après-midi de Toussaint pour lequel elle disposera d'une image nette, une sorte de fait pur, une jeune femme s'accouvant dans l'herbe et se relevant en rabattant sa jupe. (ERNAUX, 2008, p.59)

Déjà, à cette distance, il ne reste du 8 mai 81 que l'image, dans la rue déserte, d'une femme d'âge mûr promenant lentement son chien alors que dans deux minutes exactement sera proclamé sur toutes les chaînes de télé et les radios le nom du prochain président de la République - celle de Rocard jaillissant comme un ludion sur l'écran, Tous à la Bastille!". (ERNAUX, 2008, p.166)

Ou, ainda, de acordo com o modo que as pessoas do seu entorno apreenderam e lidaram com o fato: "Et chacun cherchait ce qu'il était en train de faire juste à ce moment où le premier avion avait touché la tour du World Trade Center, que des couples s'étaient jetés dans le vide en se tenant par la main" (ERNAUX, 2008, p.220).

Mas não é apenas o lugar social da autora ou a sua ótica em relação aos fatos que guiam as memórias coletivas: de acordo com cada momento de sua vida, o teor das memórias também muda. No período da infância e da adolescência, a memória coletiva é formada por questões sociais mais próximas do dia a dia da autora: a condição precária dos camponeses no pós-guerra ${ }^{8}$; os gestos e hábitos dessas pessoas ${ }^{9}$; as crenças e ideias comuns a esse meio social ${ }^{10}$ etc. Questões políticas só começam a aparecer com maior consistência após a foto "Classe de philosophie 1958-1959", quando a autora tem cerca de dezessete ou dezoito anos e já começa a ter mais

8 "Les voix transmettaient un héritage de pauvreté et de privation antérieur à la guerre et aux restrictions" (ERNAUX, 2008, p.29); "Tout ce qui se trouvait dans les maisons avait été acheté avant la guerre. Les casseroles étaient noircies, démanchées (...)" (ERNAUX, 2008, p.39).

9 "Manger en faisant du bruit et en laissant voir la métamorphose progressive des aliments dans la bouche ouverte, s'essuyer les lèvres avec un morceau de pain" (ERNAUX, 2008, p.31).

10 : "Le progrès était l'horizon des existences" (ERNAUX, 2008, p.45) ; "La religion était le cadre officiel de la vie et réglait le temps" (ERNAUX, 2008, p.47) ; "Tout le monde savait distinguer ce qui se fait de ce qui ne se fait pas" (ERNAUX, 2008, p.48). 


\section{1}

maturidade e consciência para compreender o contexto político-social. Antes disso, esse tipo de questão não estava presente em sua vida: ela absorvia os acontecimentos do mundo de maneira indireta, sem perceber. Junto à foto de 1955, por exemplo, ela expressa o fato de que muitos dos acontecimentos que a marcaram estavam "escondidos" em sua memória, só vindo à tona, mais tarde, por meio de uma espécie de memória involuntária proustiana:

Qu'y a-t-il en elle comme savoir sur le monde, en dehors des connaissances accumulées jusque dans cette classe de quatrième, quelles traces des événements et faits divers qui font dire plus tard "je me souviens" quand une phrase entendue par hasard les évoque?

la grande grève des trains de l'été 53

la chute de Diên Biên Phu

la mort de Staline annoncée à la radio un matin froid de mars, juste avant de partir pour l'école (...). (ERNAUX, 2008, p.58).

Junto à foto de 1957, os acontecimentos do mundo aparecem sem nenhuma importância para ela e ainda sem "traços de ideologia". Além disso, a representação que ela tem desses acontecimentos é fortemente condicionada (e limitada) às poucas ferramentas a que ela tem acesso, como os livros didáticos da escola:

Sans doute est-ce aussi à l'état de sensations, de sentiments et d'images - sans traces de l'idéologie qui les a suscités - que sont réfractées en elle les informations qu'elle reçoit sur le monde. Ainsi elle voit : (...)

l'Algérie en terre brûlée de soleil et de sang, creusée d'embuscades autor desquelles voltigent de petits hommes en burnous flottants, image elle-même issue du livre d'histoire de troisième racontant la conquête de l'Algérie en 1830 illustrée par un tableau, La Prise de la smala d'Abd el-Kader (...)

II n'y a rien de tout cela dans le journal intime qu'elle a commencé de tenir, où elle décrit son ennui, son attente de l'amour dans un vocabulaire romanesque et grandiloquent. (ERNAUX, 2008, p.70)

Há ainda momentos em que ela percebe que muitas das coisas apreendidas em um determinado período da vida só foram compreendidas mais tarde: “(...) les derniers morts d'une embuscade en Algérie, nouvel épisode des troubles dont elle saura seulement plus tard qu'ils se sont déclenchés à la Toussaint 54" (ERNAUX, 2008, p.58).

A impessoalidade da autobiografia coletiva também se manifesta no modo com o qual Annie Ernaux trata as coletividades: ela própria define a sua escrita como "plate", direta, sem interferências de comentários ou explicações. Como explica Meizoz (2010, p.115), essa escrita não se beneficia de uma superioridade irônica ou científica, não tem pretensão de julgar os valores do outro e quer apenas descrevê-los e interpretá-los dentro do contexto da cultura à qual pertencem.

Isso não impede que tenham, em Les années, alguns momentos de crítica aos objetos tratados: a autora as faz, mas sem sair do seu devido lugar social e dentro do contexto do período retratado. Ora ela se inscreve na crítica, ora alterna o "nós" e o "eles", diferenciando-se do grupo 


\title{
21
}

criticado. Por exemplo, ela descreve o comportamento da classe média francesa a partir de 1968, e diz como, na prática, a revolução ocorreu de maneira limitada. Em um primeiro momento, ela se inclui na crítica, usando o "nós "11. Entretanto, pouco depois disso, ela se desprende desse "nós" ao falar de como os camponeses pobres eram, ao mesmo tempo, fetichizados e explorados pela classe média - em uma atitude condizente à sua preocupação de não "trair" suas origens:

\begin{abstract}
À défaut de tout quitter, travail et appartement, pour s'installer à la campagne, (...), les plus assoiffés de résurrection cherchaient pour les vacances des villages isolés sur des terres rudes, dédaignant les plages où l'on bronze idiot et la province natale, plate et « défigurée " par le progrès industriel. Ils créditaient en revanche les paysans pauvres des contrées arides, inchangées en apparence depuis des siècles, d'authenticité. Ceux qui voulaient faire l'Histoire n'admiraient rien tant que son effacement dans le retour des saisons et l'immuabilité des gestes - et ils achetaient une vieille baraque à ces mêmes paysans pour une bouchée de pain. (ERNAUX, 2008, p.118)
\end{abstract}

Como tentou-se demonstrar, a autobiografia coletiva se realiza de diversas formas em Les années, seja na exemplaridade do "ela" enquanto parte de um grupo social, seja na estreita relação com o modo pelo qual ela apreende o mundo, seja ainda, nas diversas transformações da sociedade. Isso só se torna possível na medida em que a autobiografia se esvazia do "eu" subjetivo e se torna impessoal, abrindo espaço para que os "nós" que o compõem emerjam no texto e se expandam.

Até aqui, a escolha do "ela" e do "nós" foi vista como uma metodologia de escrita utilizada pela autora para que ela pudesse concretizar o seu desejo de salvar o tempo comum que a atravessou ao longo de sua vida. A seguir, essa escolha será analisada pelo seu negativo, considerando a recusa que ela implica: a do uso do "eu".

\section{A recusa do "eu" autobiográfico como escolha enunciativa}

De início, faz-se necessário mencionar a proximidade da concepção da autobiografia impessoal e coletiva à sociologia de Pierre Bourdieu. Inizan (2015), em seu texto, estabelece diversas relações entre a metodologia do sociólogo e a de Annie Ernaux, aproximando-as pela maneira como cada autor utiliza o "conhecimento pelo corpo", o "conhecimento prático", proporcionado pelo lugar do sujeito no mundo:

Si la "double inclusion" permet au sociologue de ressaisir le processus de l'habitus et de l'incorporation, c'est d'une façon très comparable que l'écriture d'Annie Ernaux, à partir de la tension produite entre le sujet et la totalité (ou bien l'histoire), peut réinscrire le corps parmi les choses, dans un lieu, dans un espace physique et social. (INIZAN, 2015, p.11)

11 Por exemplo, na frase "Selon l'âge, le métier et la classe sociale, les intérêts et les vieilles culpabilités, on accommodait la révolution à sa mesure." (ERNAUX, 2008, p.117) 


\section{1}

Entretanto, o ato da troca do "eu" pelo "ela" e pelo "nós" vai além da inspiração bourdiana. No contexto de Les années e segundo as ideias de Annie Ernaux, essa escolha aponta também para a paradoxal incoerência de se dizer "eu" em uma autobiografia.

Em primeiro lugar, porque nenhum indivíduo é o mesmo no passado, no presente e no futuro. Como a própria Ernaux diz em uma entrevista de 2016, a diferença que separa a menina de 1958 da mulher de 2013 é tão profunda, que se torna impossível afirmar que se é a mesma pessoa, intima e profundamente, em 58 e em 2013. As pessoas, de fato, tornam-se outras a cada dia, a cada ano, a cada momento da vida, a ponto de não reconhecerem a presença do próprio corpo em fotos antigas. Esse estranhamento em relação aos suscessivos "eus" é sempre lembrado em Les années nos momentos em que o "ela" da escrita se vê no passado ou se imagina no futuro:

Difficile de reconnaître l'adolescente à la pose provocante de la photo précédente d'il y a deux ans à peine dans cette fille. (...) Aucun signe sur sa figure de l'envahissement de tout son être par le garçon qui l'a déflorée à moitié cet été (...). Ni de ses faits et gestes: marcher dans les rues après les cours en espérant le revoir, rendre au foyer de jeunes filles et pleurer" (ERNAUX, 2008, p.78-79)

Il lui arrive de s'observer nue, dans la glace de la salle de bains (...). Elle s'étonne: c'est le même corps depuis qu'elle a cessé de grandir, vers seize ans. (ERNAUX, 2008, p.184)

Elle se représente ici, dans dix ou quinze ans, le caddie rempli de confiseries et de jouets pour des petits-enfants qui ne sont pas encore nés. Cette femme lui paraît aussi improbable qu'à la fille de vingt-cinq ans paraissait la femme de quarante qu'elle ne pouvait même pas imaginer être un jour et qu'elle n'est déjà plus. (ERNAUX, 2008, p.186)

Diante disso, deixar de dizer "eu" não é apenas a consequência de uma escolha metodológica, mas é também a consequência de uma restrição enunciativa da própria escrita de uma autobiografia: se dizer "eu" só faz sentido no presente da enunciação, dizer "ela"/"ele" torna-se a única forma possível para se referir aos "eus" do passado.

Em segundo lugar, não é possível dizer "eu" em uma autobiografia simplesmente porque, para Annie Ernaux, um indivíduo não é um indivíduo em si: ele é formado por todas as alteridades com as quais têm contato. A identidade, que implica uma essência inerente, fixa, é, na verdade, volátil, imprecisa, pois o indivíduo está imerso no mundo - que está em constante transformação - e é cercado pelo outro - cuja individualidade, por sua vez, é também volátil e imprecisa. Em mais de uma oportunidade, a autora afirmou não acreditar na existência da identidade:

Je ne crois pas à l'identité de la personne. On soubit toute sorte d'influence, on fait corps avec les gens de son époque... À chaque moment on vit avec les autres, avec ceux qui sont plus vieux de vous, ceux qui sont plus jeune (...) À tous moments on est traversé par le monde." (ERNAUX, entrevista, 2016). 


\section{1}

J'ai pris conscience qu'il n'existe pas d'identité. On ne sait pas qui on est, mais on peut le saisir à travers I'histoire, les époques. Moi, je suis faite de mes époques successives." (ERNAUX, entrevista, 2008).

Assim, no limite, dizer "eu" torna-se uma convenção discursiva que apenas distingue "quem fala", de "de quem se fala" e de "para quem se fala", pois "eu", enquanto ser no mundo, fora do discurso, nada mais é do que uma combinação de um conjunto de "nós": família, amigos, amantes, colegas da escola, pessoas da mesma classe social, pessoas do mesmo gênero, coterrâneos...

Em diversas passagens do Les années é expressa essa ideia de que um indivíduo é formado por múltiplos "outros". Logo no início, por exemplo, ao tratar dos camponeses, a autora fala da herança dos gestos, transmitidos de corpo em corpo, ao longo das gerações - fenômeno que as fotos, por si só, são ineficazes para registrar:

(...) Les façons de marcher, de s'asseoir, de parler et de rire, héler dans la rue, les gestes pour manger, se saisir les objets, transmettaient la mémoire passée de corps en corps au fond des campagnes françaises et européennes. Un héritage invisible sur les photos qui, par-delà les dissemblances individuelles, l'écart entre la bonté des uns et la mauvaiseté des autres, unissait les membres de la famille, les habitants du quartier et tous ceux dont il était dit ce sont des gens comme nous. Un répertoire d'habitudes, une somme de gestes façonnés par des enfances aux champs, des adolescences en atelier, précédées d'autres enfances, jusqu'à l'oublie. (ERNAUX, 2008, p.31)

A mesma reflexão aparece quando a autora percebe-se falando como a própria mãe, adquirindo consciência do quanto ela possui em si mesma traços dos seus familiares e de todos seus ascendentes:

De sa mère, elle se rappelle les yeux, les mains, la silhouette, pas la voix, ou sinon de façon abstraite, sans grain. La vraie voix est perdue, elle n'en possède aucune trace matérielle. Mais des phrases lui viennent souvent spontanément aux lèvres, que sa mère utilisait dans le même contexte, des expressions qu'elle n'a pas le souvenir d'avoir utilisées avant, « le temps est mou », «il m'a tenu le crachoir », « chacun son tour comme à confesse », etc. C'est comme si sa mère parlait par sa bouche et avec elle toute une lignée de gens. (ERNAUX, 2008, p.185)

Diversos trechos do Les années deixam claro o quanto a convivência faz com que as pessoas absorvam umas às outras apenas compartilhando momentos em comum:

Les vingt-six élèves de la photo ne se parlent pas toutes entre elles. Chacune n'adresse la parole qu'à une dizaine, ignorant les autres et ingnorées d'elles. (...) Cependant, d'heure de métaphysique en heure de gym, toutes les voix qui répondent 'présent' à l'appel, toutes les particularités physiques et vestimentaires dans unes et des autres sont imprimées dans les consciences si bien que chaque fille de la classe 


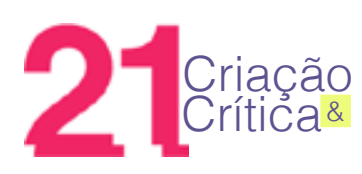

possède en elle un échantillon de la personnalité des vingt-cinq autres." (ERNAUX, 2008, pp.77-80)

Et regardant, écoutant ces enfants devenus adultes, on se demandait ce qui nous liait, ni le sang ni les gènes, seulement le présent de milliers de jours ensemble, des paroles et des gestes, des nourritures, des trajets en voiture, des quantités d'expériences communes sans trace consciente. (ERNAUX, 2008, p.200)

À son mari elle ne pense presque jamais, cependant elle porte en elle l'empreinte de leur vie commune et des goûts qu'il lui a donnés, Bach et la musique sacrée, le jus d'orange matinal, etc. (ERNAUX, 2008, p.185)

A mídia também é retratada como um fator essencial para a homogeinização dos indivíduos e para a consequente inexistência de identidades singulares e fixas. As pessoas têm a tendência de seguir os mesmos códigos sociais, a vestirem as mesmas roupas e a terem os mesmos hábitos do grupo ao qual se identificam - e muitas dessas coisas são definidas pela mídia. Propagandas, programas televisivos, jornais e revistas exercem um papel fundamental na construção dos valores e hábitos de uma coletividade e, por consequência, dos indivíduos que a compõem: "Elle se sent en coïncidence avec le mouvement de l'époque tel qu'il est tracé dans Elle ou Marie Claire pour les femmes de la classe moyenne et supérieure dans la trentaine." (ERNAUX, 2008, p.184).

Evidentemente, além do nível econômico, há diversos outros fatores determinantes para a construção das coletividades, como o gênero. As mulheres, por exemplo, carregam, conscientes disso ou não, diversos fardos que interferem radicalmente em suas experiências no mundo e que, ao mesmo tempo, as unem enquanto coletividade:

Quand elle attend à la caisse de l'hypermarché, il lui arrive de penser à toutes les fois où elle s'est trouvée ainsi dans une file, avec un caddie plus ou moins plein de nourriture. Elle voit des silhouettes imprécises de femmes, seules ou accompagnées d'enfants tournoyant autour du chariot, des femmes sans visage, juste dissemblables par la coiffure - un chignon bas, des cheveux courts, milongs, au carré - et les vêtements - ce maxi-manteau des années soixante-dix, ce trois-quarts noir des années quatre-vingt -, comme des images d'elle, détachées, désemboîtées les unes des autres à la manière des poupées russes. (ERNAUX, 2008, p.186)

Nessa rememoração proustiana atualizada (os quartos são substituídos por filas de supermercado!) a autora tem a sensação de estar essencialmente ligada a todas as mulheres presentes nas filas, locais historicamente destinados a serem ocupados por elas, as "responsáveis pelo lar". Ela torna-se todas e todas tornam-se ela, justamente por compartilharem as mesmas experiências enquanto mulher. Afinal, como se diz no trecho citado, apesar de "imprecisas", desconhecidas, diferentes entre si, ainda assim, as silhuetas possuem algo em comum: são silhuetas de mulher. 


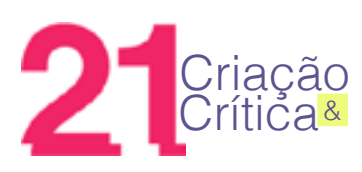

Diante de todos os modos com os quais individualidade e coletividade estão intrinsecamente relacionados, torna-se quase ingênuo dizer "eu" em uma autobiografia, quando, na verdade, o "eu" é algo que escapa a uma definição o todo tempo: ele está em constante mudança e é incessantemente atravessado pelo mundo. O "eu" é sempre um "eu" diferente e é vários "nós" ao mesmo tempo.

Além disso, a grande parte das experiências ao longo de uma vida não são únicas, excepcionais ou especialmente diferentes das de todos os outros que são parte de uma mesma coletividade. As experiências são, quase sempre, compartilhadas, mas também coletivas, ainda que cada indivíduo as perceba como únicas, já que elas se diferenciam por um detalhe ou outro:

Je crois que j'écris parce que je ressemble à tout le monde. C'est la partie de moi qui ressemble à tout le monde qui veut écrire. (...)

Le "je" ne serait pas tant le dépositaire d'une individualité, d'une vision particulière, mais tout au contraire celui d'une expérience sinon générale, au moins partagée en commun par un grand nombre de personnes. (...) Je suis, j'ai été, traversée d'émotions, marquée par des faits qui ne m'appartiennent pas en propre. II n'y a pas de "moi", de personne en soi, d'individu. On est le produit de différentes histoires familiales, de la société. (apud: CHARPENTIER, 2006)

Nesse sentido, como Annie Ernaux reconhece os indivíduos não como depositários de individualidades ou de visões particulares, mas de experiências gerais ou compartilhadas, a recusa do "eu" e o esforço por afastar-se da subjetividade são, para ela, necessários quando se quer falar do mundo. Então, para além de uma escolha metodológica e de uma restrição enunciativa dada pela condição volátil e múltipla da identidade, a recusa do "eu" se mostra também como um critério de "verdade" para tratar da realidade:

Écrire la vie, pour moi, c'est pas (sic) écrire ma vie. C'est écrire la vie tel qu'elle m'a été donnée depuis ma naissance, tout ce qui m'est arrivé, qui, au fond, est très banale. J'ai pas (sic) eu l'impression d'avoir une existence particulière. De moins, les événements qui me sont arrivées n'ont rien de particulier, cette matière là, qui est une vie, j'en extirpe quelque chose que je pourrais dire rélevée de la réalité, de la vérité. Au fond, la vie elle est donnée à tous avec le plaisir, le corps, l'éducation, l'enfance (...). Il y a l'amour, la perte de gens qu'on aime (...). C'est un ensemble. À partir de ce qui m'est arrivé à moi, me mettre à distance, ça est (sic) três importante, c'est-à-dire, de pas du tout chercher à dire "qui suis-je" (...) [il s'agit de] mettre au jour des choses, géneralement cachées, ou dont on ne parle pas. (ERNAUX, entrevista, 2011).

Escrever a partir da própria experiência para apresentar a "dimensão vivida da História", recusando-se a dizer "eu", inscreve-se ainda na postura antificcional da autora que, ao lado das posturas metodológicas e enunciativas já mencionadas, é também reveladora de uma postura ética. 


\section{1 cricáa}

\section{A recusa do "eu" autobiográfico como postura ética}

Desde Proust, a ideia de se retratar a impossibilidade de conhecer e compreender a realidade do outro foi amplamente explorada, principalmente pelos autores do Nouveau Roman que, por exemplo, construíam narrativas inteiras sem nenhuma submerção na interioridade dos personagens. Entretanto, alguns autores contemporâneos, como é o caso de Annie Ernaux, dão um passo além ao preocuparem-se não com a ilusão de se retratar a subjetividade do outro, mas com a ética da representação do outro. Essa ética envolve conceitos como, entre outros, lugar de fala, testemunho e negação da ficcionalização das experiências vividas. Os dois primeiros, relacionados à legitimidade de quem fala, já foram tratados, ainda que indiretamente, quando se mostrou o modo como a autobiografia coletiva é construída em Les années: a partir do testemunho de um "ela", que é o único que pode ser verdadeiramente acessado pela autora, e a partir dos lugares sociais que esse "ela" ocupa em cada momento da sua vida e que legitimam a apresentação das suas experiências.

Não cabe aqui aprofundar-se detidamente nesses dois conceitos, mas vale mencioná-los como parte da ética adotada por Annie Ernaux em sua escrita. Além disso, é importante trazê-los à luz por serem elementos que estão intimamente ligados à recusa da ficção, condição de escrita obrigatória para a escritora.

Para evocar a questão da antificcionalização, pode-se citar Marcel Cohen, autor francês contemporâneo que também recusa a ficção em nome da ética da representação. Ele afirma, por exemplo, que nada deve se substituir ao testemunho dos antigos deportados, quando se trata de representar a Catástrofe da Segunda Guerra Mundial:

Eis porque cada antigo deportado, por mais modesto que possa parecer seu testemunho, representa uma chance para se aproximar do imenso buraco negro no qual se afundou toda uma civilização. Nenhum detalhe é irrelevante e cada voz é uma ocasião única para se olhar um pouco mais de perto, como quem explora uma ruína com uma lanterna (COHEN, 2018, no prelo).

Além de valorizar, acima de tudo, o testemunho de quem vivenciou a Catástrofe, Cohen também afirma que a estética utilizada na literetura e no cinema que tratam desse tema assemelhase a uma "depravação moral". E é por isso que, segundo ele, a única função da ficção, nesses casos, é a de "mascarar as realidades ao invés de revelá-las. Ou, ao menos, torná-las mais toleráveis" (COHEN, 2018, no prelo).

Embora seja necessário guardar as devidas proporções entre os temas tratados na obra de Ernaux e de Cohen, pode-se aproximar os dois autores na medida em que ambos recusam a ficção e a consequente estetização das experiências vividas, sejam elas traumáticas ou não. Para eles, essa é uma condição indispensável quando se quer tratar de fatos da realidade de maneira ética, evitando a banalização das experiências e a produção de um pathos que mascara a realidade. Em La place (2018, p.24), livro em que Ernaux tenta reconstituir a vida do pai, ela vai justamente nesse sentido ao dizer que não tem o direito de tomar o partido da arte e criar algo permeado de emoções e paixões para dar conta de uma vida submetida à precariedade, como foi a do pai. E, em Les années, essa preocupação é semelhante, já que nele a autora 


\section{1}

pretende recuperar e salvar uma realidade compartilhada, o tempo comum e, por isso, não tem o direito de estetizá-los.

A recusa da ficção como rejeição da estetização da experiência vivida expressa-se também no uso da "écriture plate", direta, objetiva, simples, que, como já se mencionou, não tem pretensão de julgar os valores do outro:

Quand elle désirait écrire, autrefois, dans sa chambre d'étudiante, elle espérait trouver un langage inconnu qui dévoilerait des choses mystérieuses, à la manière d'une voyante. Elle imaginait aussi le livre fini comme la révélation aux autres de son être profond, un accomplissement supérieur, une gloire (...). Par la suite, dans des classes brutales de quarante élèves, derrière un caddie au supermarché, sur les bancs du jardin public à côté d'un landau, ces rêves l'ont quittée. II n'y avait pas de monde ineffable surgissant par magie de mots inspirés et elle n'écrirait jamais qu'à l'intérieur de sa langue, celle de tous, le seul outil avec lequel elle comptait agir sur ce qui la révoltait. Alors, le livre à faire représentait un instrument de lutte. (p.252)

A partir desse trecho do projeto de escrita de Les années, percebe-se como a postura antificcional e o uso de uma linguagem totalmente despida de preciosismos e afetação fazem parte de uma ética que é também contestatória. Por um lado, a autora se opõe à literatura tradicional, considerada superior, produzida com a linguagem da elite e para a elite, e que se diz reveladora de um mundo inefável, totalmente distante da realidade brutal do quotidiano. De fato, a visão de Annie Ernaux em relação à sua própria prática literária baseia-se na total dessacralização da literatura. Ao falar sobre seu processo criativo, ela diz que escreve no verso de folhas A4 já "usadas" (uma carta inacabada, um boleto, um fôlder), para certificar-se de que está retirando todo o caráter solene da escrita (ERNAUX, 2011, p.9). Isso se relaciona diretamente com a sua preocupação de não "trair" a sua origem por meio de uma linguagem afastada da realidade a qual ela pertenceu (e ainda pertence de alguma forma). Refletindo sobre isso em seu diário de escrita, publicado sob o título de L'atelier noir, ela diz:

[L'atelier noir] est né de mes problèmes à transcrire la réalité et la vision du monde de mes ascendants dans une forme littéraire qui ne les trahisse pas. Pour le transfuge ou l'exilé, rien ne va de soi dans la vie sociale, non plus dans l'écriture. Peut-être éprouvet-il plus qu'un autre écrivain la fragilité et l'arbitraire de la nomination des choses, plus qu'un autre est-il au cœur de l'impérialisme de la langue dont parle Barthes. (ERNAUX, 2011, p.13)

Assim, por outro lado, essa ética contestatória é também uma forma de dar voz a uma parte dos excluídos da sociedade e, consequentemente, restituir-lhes a existência, já que "o falar não se restringe ao ato de emitir palavras, mas de poder existir" (RIBEIRO, 2017, p.64, grifo nosso) e, como já foi dito, não existe experiência humana fora da linguagem. No contexto do Les années, percebe-se que o desejo de salvar, pela escrita e na escrita, o que foi vivido e está prester a desaparecer anda ao lado da necessidade de se incluir na literatura quem é dela excluído. Édouard Louis, jovem escritor francês influenciado por Ernaux, que também é um "desertor de classe" e 


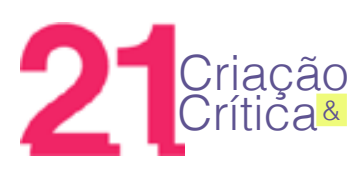

escreve textos autobiográficos, utilizou uma expressão que dialoga com esse desejo da autora de inclusão: ele opera uma "espécie de vingança contra a literatura" (LOUIS, 2018), incluindo "a realidade que ela excluía", a realidade da população que está à margem da sociedade e é submetida à diversas violências, tais como a privação da cultura. Com isso, a preocupação ética de autores como Annie Ernaux, Marcel Cohen e Édouard Louis é justamente de dar legitimidade e visibilidade, a partir de seus lugares de fala, às narrativas que são geralmente desprezadas ou omitidas, e, assim, refutar a "historiografia tradicional e a hierarquização de saberes consequente da hierarquia social" (RIBEIRO, 2017, p.64).

É certo que, em Les années, não aparece apenas a voz de classes inferiorizadas na sociedade. Mas essa contestação da "hierarquização de saberes" não se dá apenas por meio da reprodução da voz dos outros: a "écriture plate" impessoal, por um lado, e o testemunho das vivências da autora e do modo com o qual o mundo reagiu à sua existência, por outro, já significam, por si só, a inclusão, na literatura, do excluído.

Além disso, no caso de Annie Ernaux, essa ética da representação, que tem também função contestatória, se dá na medida em que a sua subjetividade se dissolve totalmente na coletividade, o que incorre no abandono da posição de superioridade do autor onipotente. De fato, para não ficcionalizar a vida, é preciso partir do próprio testemunho, mas, como o indivíduo não é apenas um "eu", para retratar diferentes tempos comuns, de maneira ética, é preciso desvencilhar-se dele. $\mathrm{E}$, como consequência do apagamento do "eu" autobiográfico, se dá justamente o deslocamento desse "eu" de seu lugar de maior destaque e prestígio. Como aponta Inizan (2015, p.7), o ponto de vista da autora não é nem estritamente subjetivo - o que acabaria apagando suas condições históricas e sociais -, nem estritamente objetivo a ponto de levá-la a uma posição de dominação e autoridade e a uma forma de intelectualismo, aos quais ela é avessa.

Para Inizan (2015), a expressão da memória coletiva permite criar um espaço textual que dá lugar ao próprio corpo da autora e aos objetos e memórias materiais. E à medida que a autora, testemunha de uma época, mergulha nessa memória material, ela acaba se dissipado na própria matéria de seu testemunho e se inscrevendo no texto - que, por sua vez, se torna um corpus scripti (INIZAN, 2015, p.14). Desse modo, o ponto de vista distanciado e superior é abandonado, assim como é abandonado o privilégio da representação do detentor desse ponto de vista:

Ce travail de l'écriture manifeste assurément toute une résistance à l'idéalisme, à l'intellectualisme, à l'autorité de l'auteur. Si le témoin se dissipe comme sujet spectateur, c'est pour réapparaître comme acte d'écriture (INIZAN, 2015, p.13).

Esse trabalho de resistência ao intelectualismo, ao lado da recusa da ficção e do uso do "eu", fazem com que Annie Ernaux deixe de testemunhar "sobre", e passe a testemunhar "com" e "por" (INIZAN, 2015, p.14), evitando a posição de um simples espectador que vê o mundo à distância, em posição privilegiada. É desse modo que a escrita, em sua dimensão agonística, revela toda a sua dimensão ética:

L'effort du témoin vise à abandonner la position de l'auteur comme subjectivité dominante - toute puissante dans la création d'elle-même -, cela afin de laisser paraître 


\section{1}

une subjectivité engagée dans l'histoire, de laisser émerger l'épreuve d'un corps, et en faire même le lieu d'une manifestation (INIZAN, 2015, p.13).

Prova de um corpo, lugar de manifestação, espaço de luta: a biografia impessoal, coletiva e vazia de Annie Ernaux, mais do que ser o resultado de uma busca estética ou de uma renovação literária, configura-se como uma maneira menos ingênua e mais ética de se representar uma vida. Menos ingênua do que uma autobiografia tradicional, porque recusa a identidade fixa e unívoca do "eu"; e mais ética do que as diversas formas de ficcionalização das experiências, que, muitas vezes, acabam estetizando e mascarando a realidade brutal do quotidiano.

Agradecimentos: Eliana, Maisa, Luiz, Verónica, Adriana, Guilherme, Lucas e Renata.

\section{Referências}

BENVENISTE, É. "Categorias de pensamento e categorias de língua". In: Problemas de Linguística Geral I. Campinas: Pontes, 1995.

"Da subjetividade na linguagem". In: Problemas de Linguística Geral I.

Campinas: Pontes, 1995.

CHARPENTIER, I. Quelque part entre la littérature, la sociologie et l'histoire. COnTEXTES,

Liège, n.1, set-2006. Disponível em: <http://journals.openedition.org/ contextes/74?lang=en\#quotation $>$. Acesso em: 12-dez-2017.

COHEN, M. A esfera de Magdeburgo. Rio de Janeiro: Zazie Edições, 2018. No prelo.

ERNAUX, A. Les années. Paris: Gallimard, 2008.

"Préface". In: L’Atelier noir. Paris: Conti, 2011.

; JEANNET, F. L'Écriture comme un couteau. Paris: Éditions Stock, 2003.

; La place. Paris : Gallimard, 2018.

Annie Ernaux [fev-2008]. Ferniot Christine e Delaroche Philippe. L'Express.

Paris, 01-fev-2008. Jornal on-line. Disponível em: <http://www.lexpress.fr/culture/livre/annieernaux_813603.html>. Acesso em: 22/10/2017.

Annie Ernaux: écrire la vie [dez-2011]. François Busnel. Paris: France 5, 2011. 2 minutos. Entrevista concedida ao programa La grande librairie. Disponível em: <https://www.youtube.com/watch?v=gsYTdeCXiGA>. Acesso em: 11/12/2017.

Annie Ernaux, Dialogues littéraires [jun-2016]. Laurence Bellon. Brest: Librairie Dialogues, 2016. 32 minutos Entrevista concedida ao programa Dialogues littéraires. Disponível em: <https://www.youtube.com/watch?v=x4snfT63vss>. Acesso em:11/12/2017.

; LAURENS, C. «Toute écriture de vérité déclenche les passions». Raphaëlle Rérolle. Le Monde livres. Paris, 03-fev-2011. Jornal on-line. Disponível em: <http://www.lemonde.fr/ livres/article/2011/02/03/camille-laurens-et-annie-ernaux-toute-ecriture-de-verite-declenche -les-passions14743603260.html\#6aW7z4c47wyfkvtf.99Ce>. Acesso em: 12/12/2017.

INIZON, Y. "Apparition et disparition du témoin: 'l'autobiographie vide'”. In: FORT, P.(dir.); HOUDART-MEROT, V. (dir.). Annie Ernaux: Un engagement d'écriture. Paris: Presses Sorbonne Nouvelle, 2015. Disponível em: <http://books.openedition.org/psn/157>. Acesso em: 24-out-2017. 


\section{1}

MEIZOZ, J. Éthique du récit testimonial: Annie Ernaux. Nouvelle revue d'esthétique, vol.6, n.2, pp.113-117, 2010. Disponível em: <http://www.cairn.info/revue-nouvelle-revue-d-esthetique2010-2-page-113.htm>. Acesso em: 22-out-2017.

LOUIS, E. Édouard Louis volta à infância miserável para investigar as origens da violência [jun-2018]. Maria Fernanda Rodrigues. Estadão. São Paulo, 16-jun-2018. Jornal on-line. Disponível em: $<$ https://cultura.estadao.com.br/noticias/literatura,edouard-louis-volta-a-infancia-miseravelpara-investigar-as-origens-da-violencia,70002352231>. Acesso em: 19/09/2018.

RIBEIRO, Djamila. O que é lugar de fala?. Belo Horizonte: Letramento, 2017.

ROUSSEAU, C. Annie Ernaux: dans la lumière du passé. Le Monde, 07-fev-2008. Disponível em: <http://www.lemonde.fr/livres/article/2008/02/07/annie-ernaux-dans-la-lumiere-dupasse_1008393_3260.html\#e8QhOLr7KkIM7Kjd.99>. Acesso em: 22/10/2017.

Recebido em: 10/02/2018 Aceito em: 30/09/2018

Referência eletrônica: CARDOSO, Raíssa Furlanetto. A recusa do "eu" autobiográfico em Les années. Criação \& Crítica, n. 21, p.37-58, nov. 2018. Disponível em: <http://revistas.usp.br/ criacaoecritica>. Acesso em: dd mmm. aaaa. 